\title{
Favela: Paisagem Cultural. Contradições vividas nas favelas da Babilônia e Chapéu Mangueira no contexto de grandes eventos e do Programa Morar Carioca Verde
}

\author{
Tatiana Terry
}

\begin{abstract}
Doutoranda pelo Programa de Pós-Graduação em Urbanismo (PROURB-UFRJ), integrante do Laboratório de Urbanismo e Meio Ambiente do PROURB UFRJ e professora do Departamento de Arquitetura e Urbanismo da PUC-Rio.

Contato: tatiana.terry@puc-rio.br
\end{abstract}

\section{RESUMO}

Os anos pré-olímpicos no Rio foram intensos e conjugaram uma série de iniciativas de promoção da cidade no contexto do "citymarketing" com enfoque na exaltação da paisagem, reconhecida pela UNESCO em 2012 como patrimônio mundial, e na divulgação de boas práticas em sustentabilidade urbana que vinham sendo implementadas. $\mathrm{O}$ artigo busca refletir sobre o papel das favelas cariocas, ou pelo menos parte delas, que a partir da ocupação pelas Unidades de Polícia Pacificadora, passaram por mudanças aceleradas sendo integradas aos circuitos turísticos e culturais da cidade . Vamos utilizar as Favelas da Babilônia e Chapéu Mangueira como referência, pela identificação ecológica e pelas inúmeras iniciativas que ali ocorreram em curto espaço de tempo, chamando atenção para as contradiçôes de uma gestão pública que enaltece suas favelas como ambiente estético e cultural mas que não mergulha, de fato, na solução de seus problemas.

Palavras Chave: Favelas, Paisagem Cultural, Sustentabilidade urbana, Turismo

\section{ABSTRACT}

The pre-olympics years in Rio were intensive and combined a series of iniaciatives to promote the city in the "citymarketing" context, with approach on the exaltation of the landscape, reconized by UNESCO in 2012 as world heritage and in the dissemination of good practices in urban sustainability that were being implemented. The article seeks to reflect on the role of the slums of Rio de Janeiro, or at least part of them, which, since the occupation of the Pacifying Police Units, underwent accelerated changes, being integrated with the city's tourist and cultural circuits. We will use the Slums of Babylon and Chapéu Mangueira as reference, for the ecological identification and for the innumerable initiatives that happened there in a short time, calling attention to the contradictions of a public management that praises its slums as aesthetic and cultural environment but that does not dive, in fact, in solving their problems.

Key-words: Slums, Cultural Landscape, Urban Sustainability, Tourism 


\section{Bloomberg na Babilônia}

Em 19 de junho de 2012 as favelas da Babilônia e Chapéu Mangueira foram visitadas por Michael Bloomberg, ex-prefeito de Nova York. Como outros 58 prefeitos das maiores cidades do mundo, ele veio ao Rio de Janeiro para participar da Rio + 20, Conferência das Naçôes Unidas sobre Desenvolvimento Sustentável. Chegou às favelas do Leme convidado pelo prefeito Eduardo Paes para ver de perto como a cidade vinha incorporando os conceitos de sustentabilidade na urbanização de favelas e como vinha incentivando parcerias públicoprivadas coerentes com a Economia Verde ${ }^{1}$.

Bloomberg ficou bem impressionado com o resultado da urbanizaçấo, com a cordialidade dos moradores e iniciativas ambientais. Muito impactado com a beleza do bairro de Copacabana que pôde ver de cima do morro, não teve tempo de explorar o circuito que percorre o Morro da Babilônia e leva ao alto do Morro do Urubu, de onde se avista em 360 graus marcos da cidade como o Pão de Açúcar, Morro do Corcovado, Favela Santa Marta e o Morro Dois Irmãos. Do alto do morro, soldados do Forte do Vigia guardaram, no século XVIII, a Baía de Guanabara contra a invasão estrangeira; mirando por um lado, a Enseada de Botafogo e a entrada da Baía de Guanabara, e, por outro, a pequena igrejinha em homenagem à Nossa Senhora de Copacabana na deserta Praia de Sacopenapan².

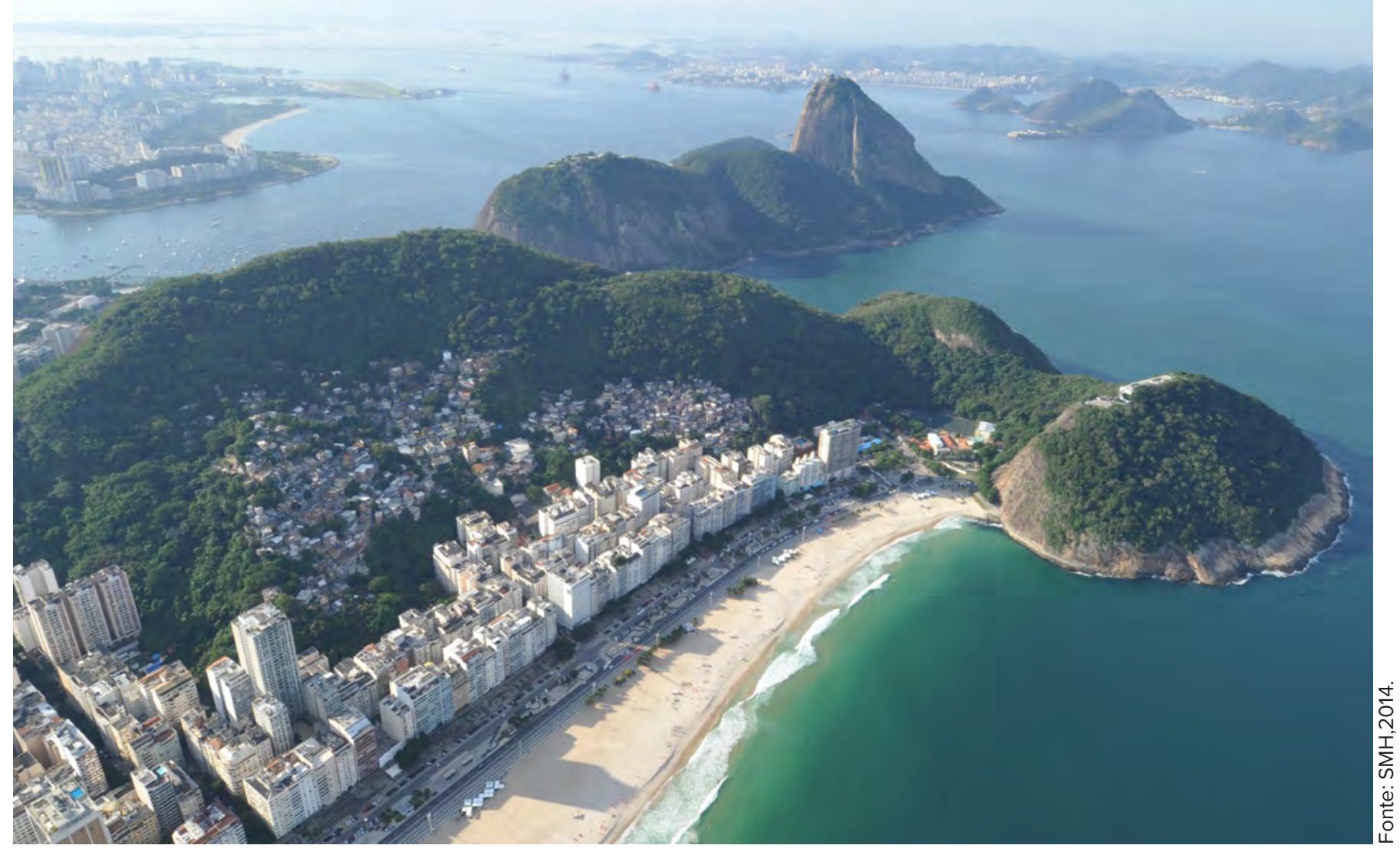

Fig. 01: Foto aérea dos Morro da Babilônia e as Favelas da Babilônia e Chapéu Mangueira.

Revista online do Departamento de Arquitetura e Urbanismo da Pontifícia Universidade Católica -

Puc-Rio - Rio de Janeiro Brasil

Ano I- No I- ISSN 2446-7340 


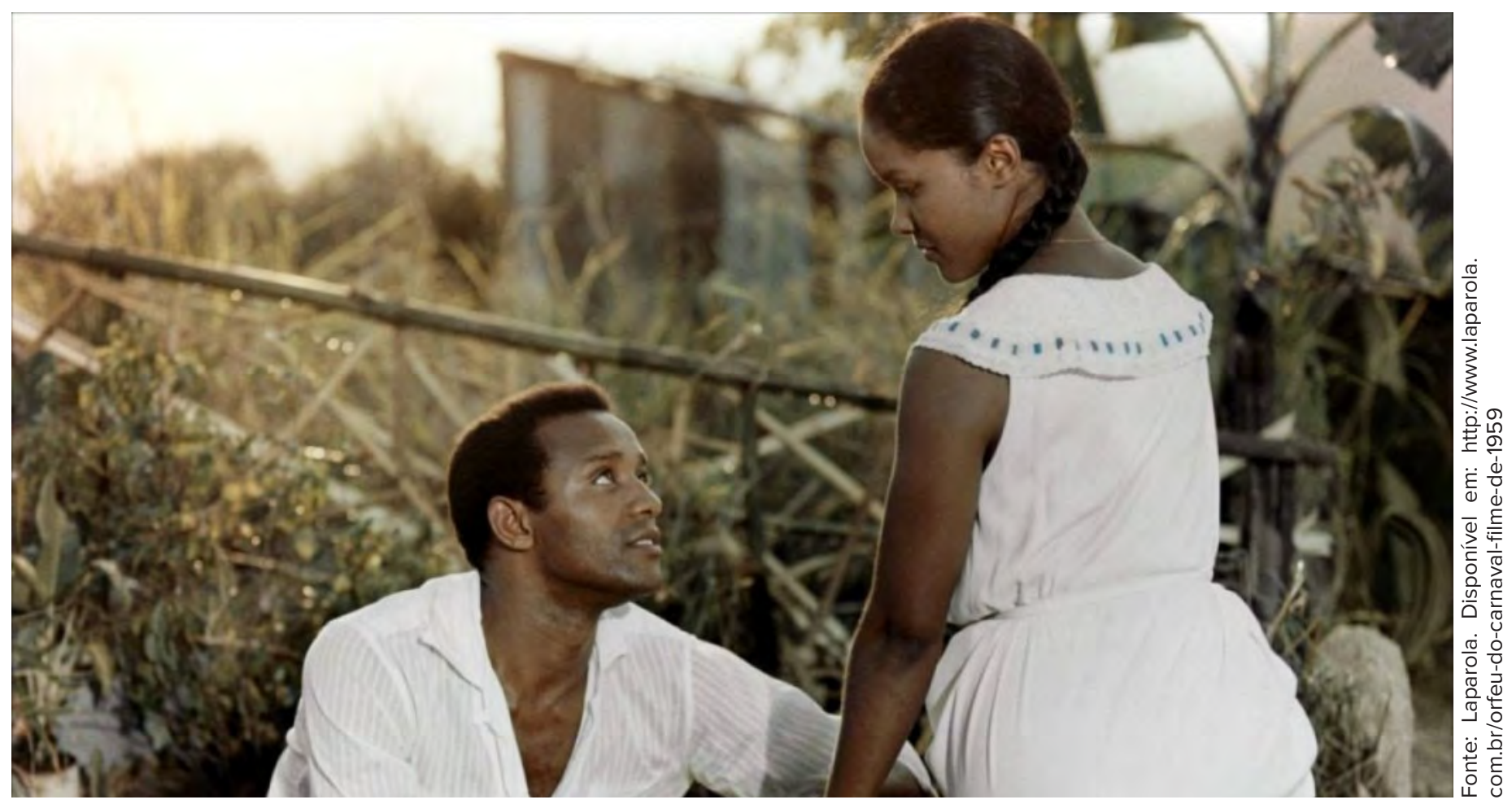

Fig. O2: Imagem do Filme Orfeu Negro, Marcel Camus 1956.

Se Bloomberg lembrasse do filme Orfeu Negro 3 , talvez reconhecesse ali as ruínas da locação da casa de Orfeu, um barraco de madeira e chão batido onde o sambista tocava seu violáo acompanhando o nascer e o pôr do sol na Cidade Maravilhosa.

\section{Origens}

As primeiras favelas do Rio de Janeiro surgiram em fins do século XIX nos morros das áreas centrais da capital devido à crise de moradia vivida pelas classes populares. Segundo Rafael Gonçalves (2013), a aboliçáo da escravatura, o crescimento da atividade manufatureira e a chegada maciça de imigrantes europeus para trabalhar nas plantaçôes de café do estado, provocaram um adensamento sem precedentes nas freguesias centrais, causando superlotação em cortiços. A reforma urbana do prefeito Pereira Passos (1903-1906) propôs remodelar o corpo da cidade colonial e, com influência do higienismo europeu ${ }^{4}$, promoveu o "bota-abaixo" dos cortiços da cidade com a justificativa de resolver os problemas de insalubridade e das epidemias. Como náo houve resposta por parte do governo para o problema de moradia para os mais pobres, que incluía ex-escravos e ex-trabalhadores rurais que sobreviviam de serviços urbanos na capital; esta população acabou improvisando abrigo nos morros próximos ao centro, dando origem a assentamentos mais densos, as favelas.

É a partir daí que os morros situados no centro da cidade (Providência, Sáo Carlos, Santo Antônio e outros), até então pouco habitados, passam a ser rapidamente ocupados, dando origem a uma forma de habitaçáo popular que marcaria profundamente a feição da cidade neste século - a favela. (ABREU, 1988, p. 66).

Revista online do Departamento de Arquitetura e Urbanismo da Pontifícia Universidade Católica -

Puc-Rio - Rio de Janeiro Brasil

Ano I - N ${ }^{\circ}$ I - ISSN 2446-7340 
Rafael Gonçalves (2013) e Valladares (2005) chamam atenção para o fato de que o fim dos cortiços não foi a única causa da formação das favelas, pois, antes mesmo da Reforma Passos, alguns morros da cidade já concentravam núcleos habitacionais de barracos. Foi o caso do Morro de Santo Antônio (1893) que chegou a ser ocupado para fins de moradia de soldados do $7^{\circ}$ batalhão do exército e dos assentamentos da Quinta do Caju e da Mangueira (em Botafogo) também surgiram no entorno de cemitérios que demandavam mão-de-obra próxima. Os autores argumentam que, apesar do senso comum das favelas serem ocupaçóes ilegais, o início de ocupação de alguns morros da cidade ocorreu de forma consentida, muitas vezes até incentivada pelo poder público ou por proprietários das terras. Como exemplo, o início de ocupação do Morro da Providência, considerada a primeira favela da cidade, que tinha na base do morro o maior e mais populoso cortiço da cidade, o Cabeça de Porco, demolido pela Reforma Passos em 1893.

Segundo estudos de Gonçalves, quando houve a demolição, um dos proprietários do cortiço permitiu que inquilinos desabrigados se alojassem no terreno que subia o morro, provavelmente cobrando-lhes aluguel por barracos que foram construídos a partir de restos de demolição do próprio cortiço. Alguns anos depois, em 1887, houve a chegada de grande número de ex-combatentes da Guerra de Canudos (1896-1897) que procuraram o comando no Palácio Duque de Caxias (Ministério da Guerra), e que, por não terem onde residir, obtiveram consentimento do exército para também ocuparem o Morro da Providência. A partir do adensamento, o morro começou a ser chamado de Morro da Favella, uma associação direta a Canudos 5 . Segundo Valladares (2005), foi a partir do Morro da Favella que a favela passou a representar uma categoria habitacional específica, aplicando-se não somente àquela localidade, mas a qualquer conjunto de barracos aglomerados e precários que logo se multiplicaram em outros morros da cidade. Segundo a socióloga, esta associação a Canudos teve um papel importante na construção do mito fundador das favelas cariocas, na origem ocupaçóes em morros associadas à ideia de resistência.

O Morro da Babilônia onde se localizam as favelas da Babilônia e Chapéu Mangueira, se situa no bairro do Leme, Zona Sul carioca, próximo ao Forte Duque de Caxias no Morro do Leme. Este forte substituiu o Forte do Vigia ou do Espia, construído entre 1776 e 1799 e que originalmente não possuía funçôes de artilharia, servindo apenas para vigília da entrada da Baía de Guanabara e como ponto de sinalização para outros fortes da cidade na ocasião da entrada de invasores. Foi uma das primeiras ocupaçóes existentes na distante Praia de Sacopenapan (Copacabana) e ligava-se à Botafogo e ao centro pelo acesso da Ladeira do Leme 6 , visto que o "Túnel Novo" só foi aberto em 1906. Algumas trilhas existentes em meio à mata ligavam os morros de São João, Babilônia e do Leme e eram utilizadas por soldados do forte que ocasionalmente circulavam pela mata. Durante a Segunda Guerra Mundial foram construídas na parte alta dos morros casamatas e outras construçôes de apoio ao exército que hoje encontram-se parcialmente preservadas.

Construçóes antigas da Favela da Babilônia, feitas em pau-a-pique, ainda podem ser encontradas na parte alta do morro, comprovando o relato de moradores de que o processo de ocupaçáo da favela ocorreu de cima para baixo justamente porque o acesso mais antigo ao Leme era feito pelo alto, pela Ladeira do Leme; e que os primeiros moradores da favela foram soldados que serviram no Forte do Leme. Segundo 
moradores do Chapéu Mangueira ${ }^{7}$ a ocupação foi consentida pelo comando do quartel da Praia Vermelha, corroborando para a tese de Gonçalves de que a ocupação inicial de alguns morros da cidade para fins de moradia ocorreu com anuência do exército.

Gonçalves (2013) lembra, que, apesar de figurarem no imaginário urbano do início do século XX como redutos anti-higiênicos e imorais, as favelas foram inicialmente toleradas pelo poder público por serem consideradas ocupaçôes transitórias ${ }^{8}$, visto que as autoridades consideravam, que, pelo nível de precariedade, as favelas ficariam insustentáveis e seriam abandonadas por alternativas habitacionais mais dignas. Tal tolerância começa a mudar quando a populaçáo urbana triplica e os dejetos produzidos pela favela passaram a impactar a cidade. A partir do momento que passaram a ser notadas, as favelas começaram a ser taxadas de ocupaçóes degradadoras

\section{do meio ambiente.}

Recorrentemente, ao longo da história, narrativas ambientalistas retrataram as favelas como "predadoras de floresta”, legitimando a ideia de uma localização imprópria, o que, para Henri Ascelrad (2009), revela outra dicotomia, a que opóe a cidade formal e a parte da cidade entendida como irregular, fundindo discursos ambientais e de estratificação social que legitimaram políticas remocionistas.

As favelas de Babilônia e Chapéu Mangueira começaram a superar esta representaçáo negativa na década de 1980, quando a Prefeitura da cidade iniciou um programa de reflorestamento das encostas do Morro do Urubu e Babilônia para conter a recorrência de incêndios que ameaçavam favelas $\mathrm{e}$ bairros vizinhos. A luta pelo reflorestamento envolveu moradores das favelas que criaram uma cooperativa de reflorestamento, a CoopBabilônia, conquistando o apoio da iniciativa privada e revertendo a representação negativa da favela. Ao longo dos últimos trinta anos, diversas iniciativas colaboraram para a inversão da representação de Babilônia e Chapéu Mangueira de "favelas insustentáveis" para "favelas ecológicas" (MORAES, 2013), reconhecidas como parte do patrimônio cultural da cidade, o que será analisado neste artigo dentro do contexto de marketing urbano que promove a imagem do Rio como cidade sustentável.

\section{Contexto pré-olímpico}

No contexto da economia globalizada, as cidades figuram como mercadorias disputadas nos circuitos globais do capital e das finanças. Como produtos fundamentais para o processo de circulação de capital, competem entre si para atrair grandes grupos corporativos globais, colocando em disputa as vantagens locacionais quer em termos de qualidade de vida, infraestruturas e formas culturais de cada cidade. Segundo Carlos Vainer (1999), as cidades, tornando-se mercadorias, precisam ser vendidas em um mercado muito competitivo que explica o marketing urbano como determinante no processo de planejamento e gestáo das cidades:

... quando os governos locais promovem a cidade para o exterior, desenvolvendo uma imagem forte e positiva apoiada numa oferta de infraestruturas e de serviços (comunicaçóes, serviços econômicos, oferta cultural, segurança, etc) que enxergam a atração de investidores, visitantes e usuários solventes à cidade e que facilitam suas exportações. (CASTELLS \& BORJA, 1996, apud VAINER, 1999, p.80). 
O empreendedorismo urbano passou a ser praticado na cidade do Rio de Janeiro a partir da década de 1990, quando os governos locais contrataram consultorias catalãs para ajudar a direcionar novas estratégias urbanas que colaborassem para reestabelecer a imagem da cidade no cenário de alta competitividade global em condiçôes de atrair grupos corporativos globais e sediar megaeventos internacionais. A partir dos Jogos Pan-Americanos de 2007, iniciou-se na cidade um ciclo virtuoso de grandes eventos que incluiu a Jornada Mundial da Juventude em 2011, Rio+20 em 2012, Copa das Confederaçôes em 2013, Copa do Mundo em 2014 e culminou com os Jogos Olímpicos e Paraolímpicos em 2016. Se estes eventos contribuíram para a internacionalização da cidade, por outro lado alimentaram a expectativa da população de que deixariam um legado importante para a cidade em termos de infraestrutura:

Para os cariocas os jogos transformarão a cidade. Surgirá uma nova infraestrutura urbana, novas iniciativas ambientais, físicas e sociais, além de vantagens e oportunidades para todos... A realização dos Jogos Rio 2016 também possibilitará a concretização de aspirações globais para o futuro da cidade, da região e do país com uma visão de longo prazo. Será a oportunidade de acelerar a transformação do Rio de Janeiro em uma verdadeira cidade internacional. (Dossiê de Candidatura do Rio de Janeiro como Sede dos Jogos Olímpicos e Paraolímpicos de 2016, p. 18).

No caso dos Jogos Olímpicos Mundiais, contou muito positivamente para a candidatura do Rio o alinhamento entre os três níveis de governo e os resultados positivos da política de segurança pública das Unidades de Polícia Pacificadora (UPPs) que havia sido criada pelo Governo do Estado. Como insegurança pública era uma marca muito negativa da cidade, por conta do avanço da violência envolvendo disputas entre facçôes do tráfico de drogas e com a polícia, foi montada uma estratégia inspirada na experiência de Medellín na Colômbia, que a partir de 2004 conseguiu reverter os altos índices de violência e criminalidade. A política das UPPs - Unidades de Polícia Pacificadora - visava recuperar territórios dominados pelo tráfico através da ocupação permanente da polícia em favelas estratégicas para reduzir as taxas de homicídio e os conflitos armados e durante vários anos chegou a ter resultados positivos em algumas comunidades como foi o caso de Babilônia e Chapéu Mangueira em termos de diminuiçáo de conflitos armados e ocorrência de homicídios.

Na perspectiva do Rio de Janeiro sediar as Olimpíadas de 2016, a prefeitura da cidade elaborou um planejamento para receber os jogos, definindo açôes para os quatro anos de gestão do governo municipal, o Planejamento Estratégico (2009-2012). Entre as metas estabelecidas pela prefeitura em relação às favelas, buscava-se maior controle sobre o uso do solo fiscalizando e coibindo a expansão das favelas. $\mathrm{Na}$ área habitacional foi prevista a construção de 50.000 novas unidades de habitação de interesse social concretizadas através do Programa Minha Casa Minha Vida. No campo ambiental a meta da prefeitura era tornar-se referência nacional em sustentabilidade e preservação ambiental. Para isso, além de manter a meta de despoluição das lagoa e baías, reduzir a taxa de emissão de $\mathrm{CO} 2$, ampliar a cobertura de tratamento de esgoto, constava a meta de se tornar uma das cidades com maior cobertura vegetal do mundo. No tocante às favelas a prefeitura 
apresentou a meta de reduzir as áreas ocupadas por favelas ${ }^{9}$ em 3,5\% em relação ao ano de 2008.

\section{Contradiçóes entre políticas habitacionais e ambientais}

Em abril de 2010, fortes chuvas impactaram a cidade do Rio de Janeiro e sua região metropolitana. Uma série de deslizamentos de encostas atingiram favelas implicando em perdas materiais e de vidas humanas, gerando um grande número de desabrigados. $\mathrm{O}$ caso mais crítico ocorreu no Morro do Bumba ${ }^{10}$ em Niterói, onde morreram mais de duzentas pessoas. Em favelas como a Ladeira do Tabajaras, Morro dos Prazeres e Rocinha também houve mortes e desabamentos. As chuvas fizeram a cidade parar, mas a prefeitura carioca agiu rapidamente decretando a remoção de construçóes existentes no entorno das áreas atingidas pelos deslizamentos alegando estarem em área de risco. A Secretaria de Habitação fez o cadastramento das famílias atingidas pelo desastre no Programa Minha Casa Minha Vida para compensar as moradias perdidas no desastre. Como não foram apresentados laudos técnicos confiáveis que justificassem as remoçóes, nem garantias de que o reassentamento das famílias seria feito em áreas próximas às comunidades de origem, houve protesto por parte dos movimentos sociais. A mobilização popular deixou claro que o município vinha priorizando as remoçôes em detrimento das açóes de prevenção de risco nas favelas e que a questão do risco ${ }^{11}$ vinha sendo manipulada para justificar o "encolhimento " de favelas.

Este panorama desfavorável às favelas em 2010 parece contraditório se pensamos que a prefeitura do Rio de Janeiro lançou justamente neste ano o Programa Morar Carioca - programa de urbanização e de ações de integração social das favelas considerado como evolução do Programa Favela Bairro ${ }^{12}$ da década de 1990. O lançamento do programa, que tinha como meta ambiciosa intervir em todas as favelas urbanizáveis da cidade até 2020, envolveu um amplo debate da sociedade civil, moradores de favelas e técnicos que lidavam com a questão dos assentamentos precários. Foi realizando um concurso público organizado pelo IAB RJ que selecionou 40 equipes multidisciplinares para desenvolver projetos nas comunidades beneficiadas. Apesar de tudo indicar que a expertise carioca na urbanizaçáo de favelas continuaria seu caminho evolutivo, desta vez em escala mais ampla e com possibilidade de intervençôes mais ousadas em relação à cidade e ao meio ambiente ${ }^{13}$, o que se viu foi o Programa Morar Carioca acabar atropelado pelas obras consideradas prioritárias para os grandes eventos esportivos - entre elas as obras de mobilidade -, tendo registrado um desenvolvimento pífio frente às metas estabelecidas inicialmente. Apesar do inegável fracasso na área habitacional, a Prefeitura da Cidade do Rio de Janeiro foi laureada com o Primeiro Prêmio de Liderança Climática de Cidades do C40 em 2013 com o Programa Morar Carioca.

\section{Rio +20 e Morar Carioca Verde}

Em junho de 2012, a cidade sediou um grande evento, a Rio+20- Conferência das Naçóes Unidas sobre Desenvolvimento Sustentável. Marcando os vinte anos de outra conferência ambiental na cidade, a ECO 92 ${ }^{14}$, a conferência Rio +20 teve dois enfoques principais: A Economia Verde no contexto do Desenvolvimento Sustentável e da Erradicação da Pobreza, e a Estrutura Institucional para o Desenvolvimento Sustentável. Foram recebidas 193 delegaçóes de estado e 59 prefeitos das maiores cidades do mundo com objetivo de 
discutir a renovação do compromisso político com o desenvolvimento sustentável global.

No sentido de conciliar as boas práticas ambientais com as obras que vinham sendo feitas na cidade, em 2010, a prefeitura resolveu investir na aplicação de conceitos de sustentabilidade na urbanização de áreas vulneráveis, elegendo as favelas do Chapéu Mangueira e Babilônia para serem beneficiadas. Estas comunidades, que já reivindicavam obras de urbanização desde 2004, quando as obras de urbanização do Programa Bairrinho da Prefeitura foram interrompidas, foram escolhidas por já estarem ocupadas por uma Unidade de Polícia Pacificadora desde 2008, fazerem limite com áreas de proteção ambiental (APAs) e apresentarem um envolvimento efetivo de sua população em projetos ecológicos. Além da intenção da prefeitura de testar mudanças no padrão de urbanização de favelas que vinha sendo praticado através de novos materiais, técnicas construtivas e conceitos de urbanização mais sustentáveis, esperava-se que em 2012 a obra estivesse concluída para poder ser visitada durante a Rio+20 por autoridades e outros visitantes ilustres. A ideia era proporcionar aos visitantes a oportunidade de visitar uma favela integrada a um dos principais cartôes postais da cidade para conhecer iniciativas locais alinhadas aos conceitos de sustentabilidade e coerentes com a Economia Verde.

A iniciativa de urbanização sustentável da Babilônia e Chapéu Mangueira foi chamada de Morar Carioca Verde, apesar destas comunidades não constarem da lista de favelas eleitas originalmente para serem beneficiadas pelo Programa Morar Carioca.

Apesar do fracasso do Programa Morar Carioca que enquanto política habitacional que não decolou; apesar da onda de remoçáo que tomou conta da cidade durante a preparação para os jogos olímpicos promovendo o "encolhimento das favelas" previsto no Plano Estratégico; e embora as obras do Morar Carioca Verde da Babilônia Chapéu Mangueira ainda não estivessem concluídas na ocasião da realização da Rio +20 , a visita de autoridades às favelas no evento de 2012 contribuiu para divulgar para o mundo a imagem de uma cidade reconciliada com a natureza e de uma prefeitura que, em tese, não renegava suas favelas.

As obras do Morar Carioca Verde realizadas nas comunidades de Babilônia e Chapéu Mangueira acabaram reforçando a representação de favelas ecológicas (MORAES, 2013), que, "pacificadas", tinham possibilidades efetivas de se integrar aos circuitos turísticos da cidade.

\section{Turismo nas favelas}

O turismo passou a ser uma atividade fundamental para o futuro das cidades representando novas oportunidades econômicas e de trabalho no contexto da desindustrializaçáo global e colaborando para a renovação da imagem das cidades no contexto de competição urbana que vivemos.

Para Fernanda Sanchez (1997), os interesses econômicos dominantes que determinam a forma de organização da cidade acabam por projetar anseios, necessidades e novas práticas de consumo urbano, havendo uma espécie de espetacularização do cotidiano reforçado pelo poder hegemônico da mídia, que faz com que sempre existam novos espaços da cidade a serem renovados para serem explorados como novidades. A cidade seria assim, o espetáculo e seus moradores, os figurantes. Para Sanchez, a arquitetura e a supremacia da imagem sobre o objeto alimenta a estetização da experiência urbana onde "a centralidade da forma é mais importante que a efemeridade dos espaços criados" colaborando para 
sua integração nos circuitos turísticos.

Kim \& Ross (2010) acreditam que o que move o interesse do turista pela pobreza é a busca pelo desconhecido, já Terry (2002) pontua que o turista busca o pitoresco e que isto é uma influência da cultura ocidental europeia ${ }^{15}$ tendo se tornado mais comum no Brasil no século XIX, após a chegada da Missão Francesa ${ }^{16}$. A integração recente das favelas aos circuitos turísticos da cidade revela uma aproximação a locais por muito tempo estigmatizados, ambientes pitorescos e de grande autenticidade, pela estética do ambiente construído, pela intensidade das trocas sociais e culturais e por serem pontos privilegiados de observação da paisagem. As favelas pensadas como berço do samba e do funk carioca sempre foram valorizadas como ambientes estimulantes para os artistas. Apesar do estigma da violência, recentemente passaram a ser incorporadas à cultura de massa sendo o cenário principal e tema de várias novelas ${ }^{17}$ e filmes ${ }^{18}$.

À despeito de quebrar barreiras e trazer fontes alternativas de renda, Kim \&Ross (2010) consideram que o turismo que gira em torno na pobreza não chega a alterar a condição colonizada de sua populaçáo, sendo uma experiência de consumo que alimenta, de certa forma, a "estetização da pobreza", mais uma faceta do turismo contemporâneo.

No Rio de Janeiro o turismo em favelas vem sendo

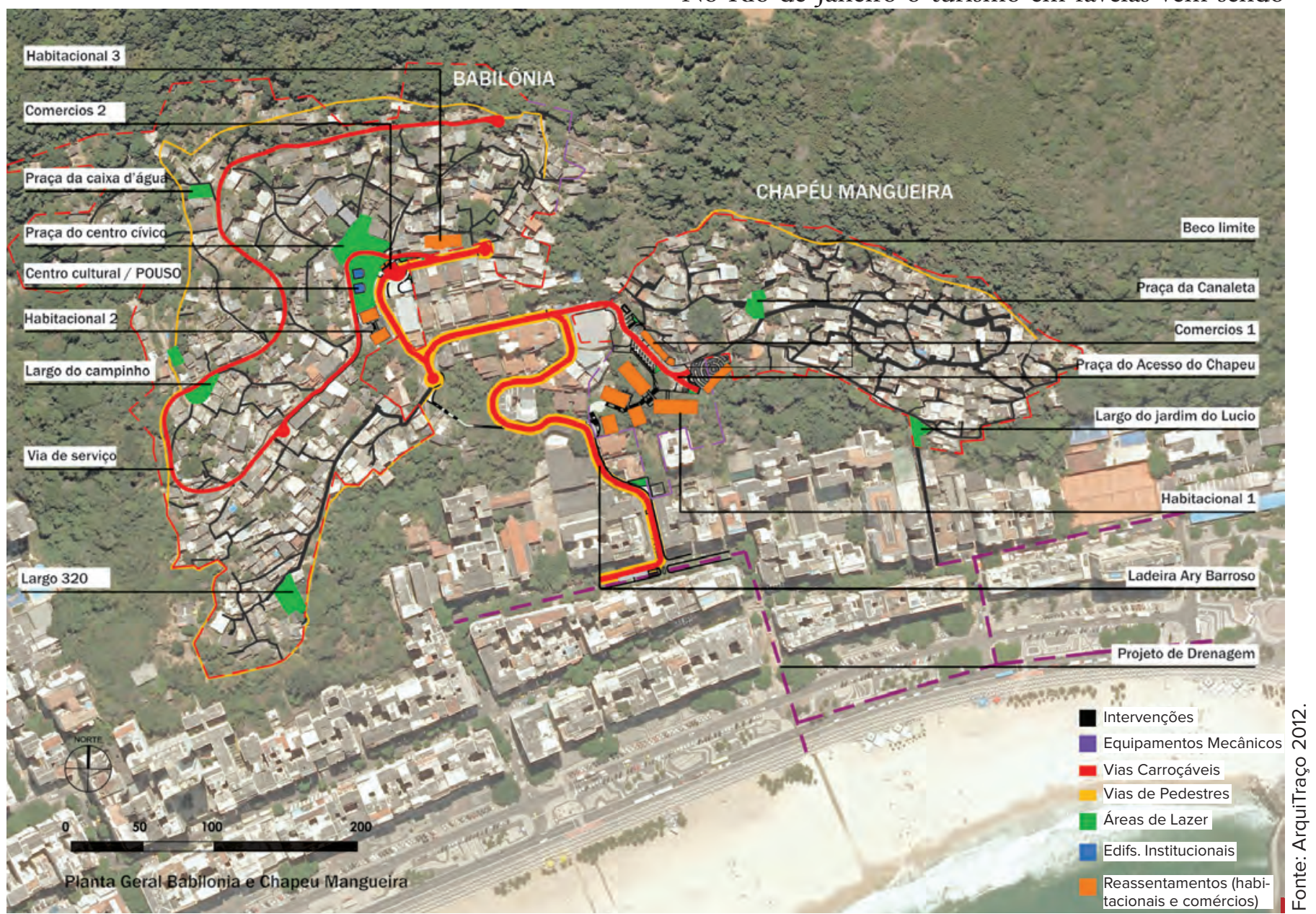

Fig. 03: Resumo das Intervençóes do Morar Carioca Verde nas Favelas de Babilônia e Chapéu Mangueira (nem todas as obras foram executadas)

Revista online do Departamento de Arquitetura e Urbanismo da Pontifícia Universidade Católica -

Puc-Rio - Rio de Janeiro Brasil

Ano I - N ${ }^{\circ}$ I - ISSN 2446-7340 

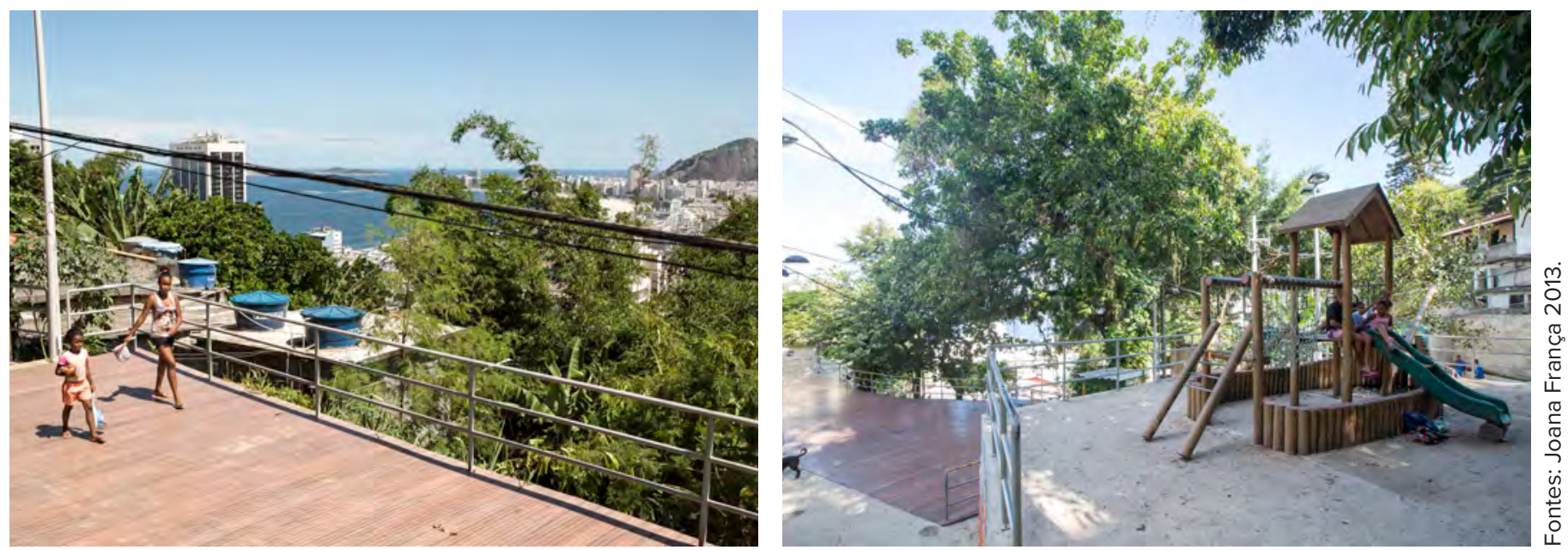

Fig. 04 e 05: Mirante e Área de lazer na favela da Babilônia - Morar Carioca Verde, projeto ArquiTraço Projetos. Fontes: Joana França 2013.
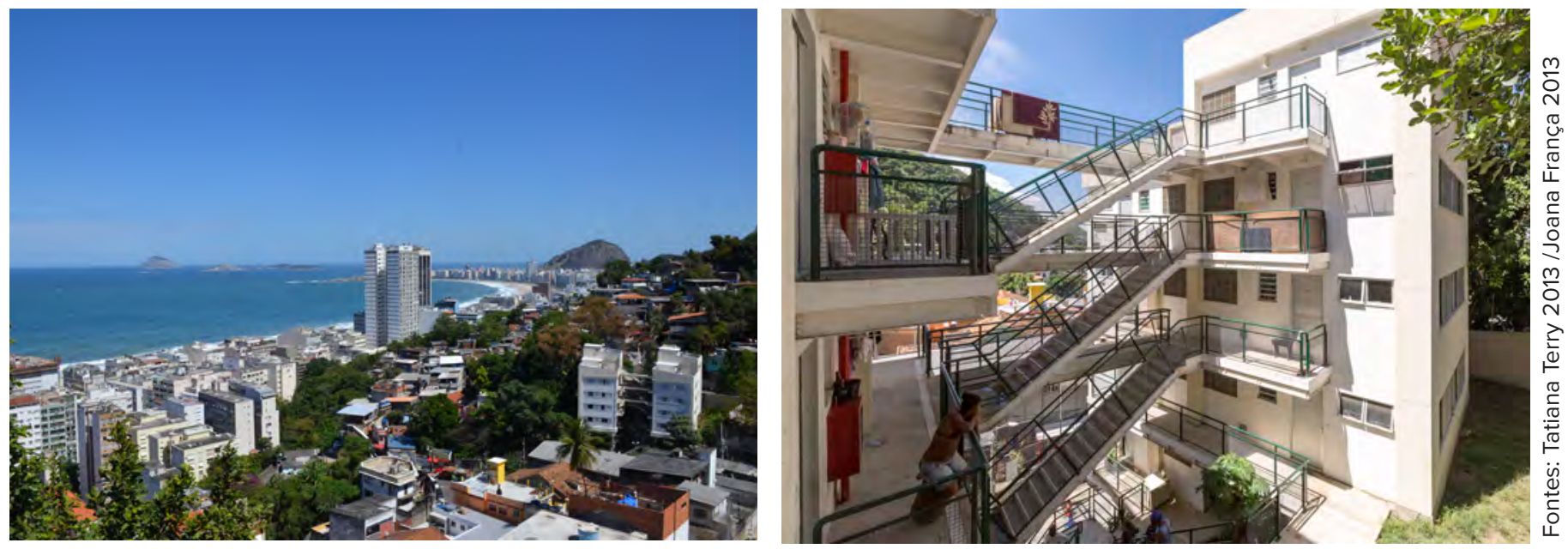

Fig. 06 e 07: Edifício HAB 2- Unidades de reassentamento Morar Carioca Verde na Favela da Babilônia. ArquiTraço Projetos.

explorado desde a década de 1990 por empresas que promovem os “jeep tours". Esse tipo de turismo é mal visto pelos moradores porque é explorado por "empresas de fora" sem retorno de lucro para as comunidades. Ademais, associa a visita à favela a uma espécie de safári urbano, o que colabora ainda mais para estigmatizar os territórios.

A partir de 2007, com a chegada das Unidades de Polícia Pacificadora em algumas favelas, houve crescimento das iniciativas ligadas ao turismo de base comunitária, aquele que envolve diretamente os moradores do lugar. Favelas contempladas com obras de mobilidade através da introdução de equipamentos mecânicos que melhoraram a acessibilidade, como o plano inclinado da Santa Marta (2008), elevador público do Cantagalo (2010) e teleféricos do Complexo do Alemão (2011) e do Morro da Providência (2013), também tiveram incremento de atividades ligadas ao turismo.

As favelas pacificadas foram beneficiadas por programas de capacitaçáo e editais culturais que estimularam o empreendedorismo voltado para o 
turismo, paralelamente à chegada de investidores de fora. Atividades como visitas guiadas, museus a céu abertos e trilhas ecológicas foram incentivadas pelo governo representando novas alternativas de renda para os moradores. Houve conversão do uso de moradias transformadas em albergues, pousadas, bares, restaurantes e até centros culturais, pois uma série de atividades culturais voltadas para o público externo, que anteriormente não ocorriam em favelas, passaram a acontecer, valorizando a condição de espaço autêntico e "descolado" que correspondem às novidades exigidas pelo consumo urbano.

Fagerlande (2017) identificou uma espécie de tematizaçáo na competiçáo que envolve algumas favelas cariocas pela atratividade turística. Conforme pôde verificar em sites, blogs e guias oficiais de turismo, algumas favelas "pacificadas" pelas UPPs, especialmente aquelas localizadas na Zona Sul, passaram a constar como atrativos turísticos da cidade, identificadas por temas, o que para o autor é um reflexo da tendência que se observa em outras cidades turísticas do mundo frente à competitividade da globalização. No Guia de Bolso das Favelas Rio lançado pelo SEBRAE em 2014, enquanto a Mangueira é tematizada como "berço do samba", o Complexo do Alemão apresenta o teleférico como atrativo. As favelas da Babilônia e Chapéu Mangueira aparecem neste guia caracterizadas pela proximidade às Praias de Copacabana e Leme; por serem pontos privilegiados de vista da paisagem carioca; pelas comodidades oferecidas ao turista, incluindo opçóes de hospedagem e gastronomia ${ }^{19}$; pela proximidade da floresta e existência de trilhas ecológicas.

As comunidades Chapéu Mangueira e Babilônia estão localizadas na encosta do Morro da Babilônia, pertencente à Área de Proteção Ambiental do Morros da Babilônia e São João. Próximas das praias do Leme e Copacabana, essas comunidades recebem visitantes que usufruem de boa estrutura de hospedagem, comida saborosa e uma bela vista do mar. Além desses atrativos, a proximidade $\mathrm{da}$ floresta também proporciona passeios em meio à natureza, com caminhadas por trilhas que levam até o topo da montanha. (Guia de Bolso das Favelas, 2014, p.6).

\section{Parque Paisagem Carioca}

A preparação da cidade para os grandes eventos ocorreu em paralelo a iniciativas para melhorar a preservação das áreas de proteção ambiental da cidade e a divulgação quase ufanista de suas belezas

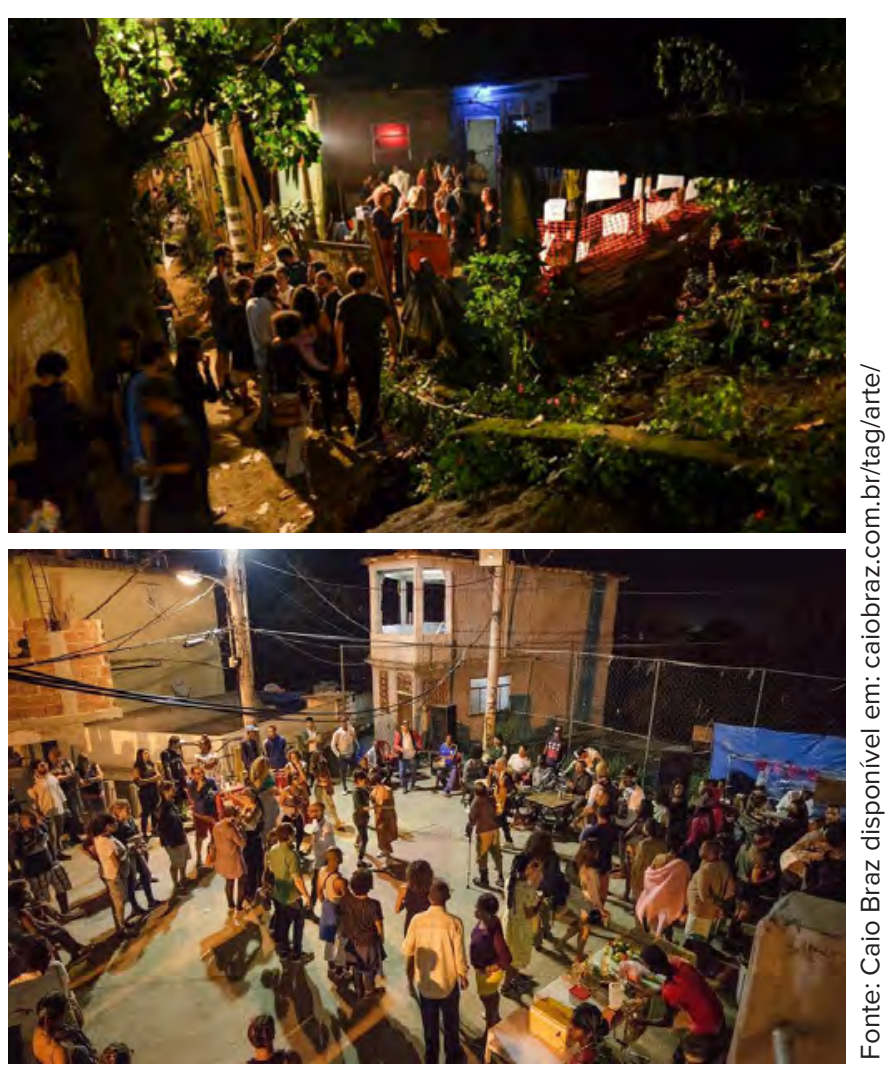

Fotos 8 e 9: Evento Cultural Jardins Suspensos Favela da Babilônia 2013. 
naturais. Um ganho importante para a imagem da cidade ocorreu logo após a realização da Rio +20 com a conquista do título de Patrimônio Mundial da UNESCO na categoria Paisagem Cultural ${ }^{20}$, o que foi considerado inédito pois foi a primeira vez que uma cidade de grande porte foi contemplada. No dossiê da candidatura, chamado "Rio de Janeiro, paisagens cariocas entre a montanha e o mar", foi dada ênfase aos elementos naturais da paisagem da cidade $^{21}$, que teve, segundo Flora Cardoso (2016), uma perspectiva muito distanciada, considerando o skyline urbano e a cadeia de montanhas como conjunto único, sem considerar particularidades de cada bairro e ignorando a presença das favelas. A conquista do título mereceu de Raquel Rolnik o seguinte comentário crítico:

Nada mais forte nesta paisagem que a presença das favelas, espaço de autoprodução da vida cotidiana de milhares de cariocas e migrantes, que, na contingência de uma cidade que os excluiu e diante da absoluta precariedade dos meios, construíram um espaço de resistência e inserção, contraditório e complexo como é a sua relação com a cidade. Agora este lugar está protegido - internacionalmente- e sua geografia de puxadinhos e pequenos lotes deve ser inscrita e consolidada em uma legislação que reconheça direitos, protegendo o lugar da arbitrariedade de remoçóes e projetos factoides. (Rolnik, 2012).

A partir do título recebido pela UNESCO e seguindo as metas ambientais dos planos estratégicos, o município criou, em 2013, no entorno das Favelas de Chapéu Mangueira e Babilônia, o Parque Natural Municipal Paisagem Carioca, reunindo o Parque da Chacrinha, a APA dos Morros da Babilônia e São João, a APA dos Morros do Leme, Urubu, Pedra e Praia do Anel e a Ilha de Contunduba. Esse parque, inserido dentro de uma concepçáo mais ampla da trilha Trans Carioca $^{22}$, foi planejado como área aberta para o lazer e para o ecoturismo, considerando a existência de trilhas históricas que remetem aos primeiros tempos de ocupação pelo exército, a existência de pontos de observação privilegiado da paisagem e o processo continuado de reflorestamento favorável a atividades ligadas à educação ambiental.

A iniciativa do reflorestamento surgiu no início da década de 1990, quando as encostas do Morro da Babilônia e do Urubu eram tomadas pelo capim colonião $^{23}$ e frequentemente eram atingidas por incêndios que ameaçavam as favelas e os bairros do entorno. Na época a Prefeitura, através da Secretaria Municipal de Meio Ambiente e Conservação, criou um projeto de reflorestamento a partir da mobilização das associaçôes de moradores da Babilônia, Chapéu Mangueira, Lauro Muller e adjacências, envolvendo moradores das favelas e o apoio do Shopping Rio Sul. A iniciativa evoluiu para a formalização de uma cooperativa de reflorestamento, a CoopBabilônia, que há mais de vinte anos desenvolve o reflorestamento continuado das encostas, além de atividades de capacitação, educação ambiental e visitas guiadas pelas trilhas ecológicas ${ }^{24}$.

A proximidade histórica com a floresta desde as primeiras ocupaçóes da encosta, a iniciativa de um reflorestamento participativo e continuado e a existência no local do ecoturismo de base comunitária foram motivos para a escolha de Babilônia e Chapéu Mangueira como projeto piloto do Morar Carioca Verde em 2010/2012 e para a criação do Parque Natural Municipal Paisagem Carioca.

Para Camila Moraes (2013) a criação da 

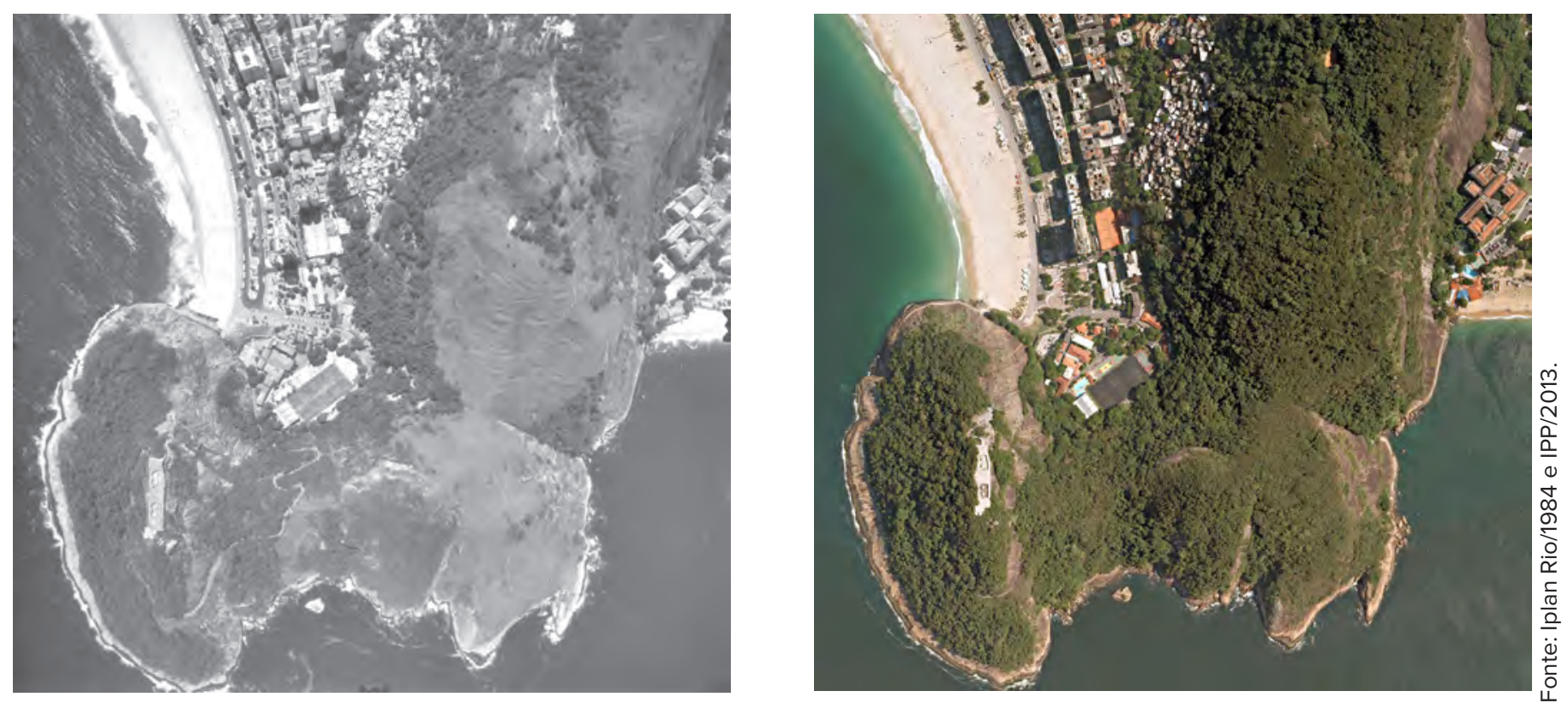

Fig. 10 e 11: Vista aérea da Pedra do Leme e Morro da Babilônia antes e depois do programa de reflorestamento que incluiu a participação da CoopBabilônia.

CoopBabilônia e das áreas de proteção ambiental dos Morros Babilônia e São João durante a década de 1990 contribuíram para o envolvimento dos moradores das favelas da Babilônia e Chapéu Mangueira com as questóes ambientais, o que contribuiu para o que chamou de "invenção da favela ecológica", invertendo o senso comum das favelas como predadoras de floresta ou degradadoras do meio ambiente.

\section{Conclusão}

Apesar da capa progressista do Programa Morar Carioca e sua aposta sustentável realizada nas favelas de Babilônia e Chapéu Mangueira, o Morar Carioca Verde, percebemos que, enquanto as açóes ambientais tiveram destaque dentro da gestáo, houve retrocesso em relação às políticas habitacionais municipais durante os anos de preparação da cidade para a Copa do Mundo e Jogos Mundiais, especialmente no que tange à remoção de favelas. Esse processo reforça a dicotomia clássica entre meio natural e ocupação humana na medida em que prioriza a paisagem natural e colabora indiretamente aos processos de estratificação social.

Para além dos propósitos ambientais da Conferência sobre o Meio Ambiente da Rio + 20, o Morar Carioca Verde, parcialmente realizado nas favelas da Babilônia e do Chapéu Mangueira, divulgou para o mundo a imagem de uma cidade que vive em harmonia com o meio ambiente e que preserva suas favelas, embora na prática o que testemunhamos na última década foi o abandono das políticas de integração urbana e social nas favelas, considerando que o Programa Morar Carioca, mostrado um salto evolutivo para uma cidade menos desigual, acabou não sendo implementado.

A patrimonialização $\mathrm{da}$ favela tem discursos contraditórios: por um lado, o crescimento da favela deve ser estancado para não ameaçar o ambiente, $\mathrm{e}$ não se aceita nenhuma mudança a não ser a mais radical delas, justamente a da remoção. Por outro lado, a favela é divulgada pelo mundo como celeiro cultural de inventividade e práticas sustentáveis que servem de lição para a cidade moderna. 


\section{Notas de fim:}

1. Economia que prioriza a baixa emissão de carbono, eficiência no uso de recursos e a busca pela inclusão social resultando na redução de riscos ambientais, bem-estar e menos desigualdade social.

2. Até o século XVIII a Praia de Sacopenapan era uma paisagem agreste e desabitada compreendendo regiáo mais vasta que ia do sopé do Morro do Leme até o Morro Dois Irmãos, incluindo também a Lagoa Rodrigo de Freitas. Com a construção de uma capela em devoção Nossa Senhora de Copacabana, santa boliviana, no promontório do posto 6 , o lugar passou a ser conhecido como Praia de Copacabana.

3. Orfeu Negro foi um filme de 1956 que retratou pela primeira vez no cinema a favela carioca, sendo protagonizado por atores negros. O filme foi uma adaptação da peça Orfeu da Conceição, escrita por Vinicius de Moraes em 1954, baseada na tragédia grega de Orfeu e Eurídice que foi romantizada na favela da Babilônia tendo como pano de fundo o carnaval. Foi uma produção ítalo-francesa-brasileira dirigida pelo francês Marcel Camus que ganhou a Palma de Ouro em Cannes em 1959 e o Oscar de melhor filme estrangeiro em 1960.

4. Segundo Pechman (2002) na Europa o higienismo e o urbanismo surgiram a partir da necessidade de reformulação urbana para atender às necessidades industriais e dar solução para o problema do adensamento dos bairros populares. No Brasil, a resposta urbana para esta "civilidade higienizada" se reduziu ao embelezamento $\mathrm{da}$ cidade, sem reverter as causas dos problemas sociais, entre elas a falta de moradia acessível para as classes populares.

5. Canudos foi um vilarejo no sertão da Bahia onde houve um movimento de resistência ao republicanismo liderado pelo religioso carismático Antônio Conselheiro. Pela tese havia um morro em Canudos conhecido como Morro da Favella, onde havia uma vegetação euforbiácea muito resistente, conhecida como favela (Jathropa phyllaconcha) motivo pelo qual o morro ganhou este nome. Quando os combatentes de Canudos chegaram de volta ao Rio e se fixaram no Morro da Providência, passaram a chamar este morro de "Morro da Favella" em alusão ao morro de Canudos.

6. Até o século XIX o bairro de Copacabana só era procurado por motivos terapêuticos ou religiosos. Terry
(2003) lembra que a ocupação residencial de Copacabana se intensificou somente nas primeiras décadas do século XX a partir de obras importantes como a eletrificação do serviço de bondes, abertura do túnel Novo (1906), abertura da Av. Atlântica (1906) e a construção do hotel Copacabana Palace (1923) que trouxeram para o local o status de "bairro elegante". Apesar do primeiro acesso por túnel (Túnel Velho) e serviço de bonde já existir desde 1892, a ocupação do bairro do Leme se intensificou somente a partir da abertura do Túnel Novo durante a Reforma Passos.

7. Fonte: Sabren (Chapéu Mangueira / Histórico. Disponível em: portalgeo.rio.rj.gov.br)

8. Lidando com a perspectiva das favelas como ocupaçóes transitórias, o Código de Obras de 1937 procurou conter sua expansão e seu desenvolvimento nas áreas centrais, proibindo novos barracos e reformas nos barracos existentes e prevendo multas para os proprietários de terras que permitissem a ocupação de favelas.

9. Lembremos que no período vivia-se o Programa Minha Casa Minha vida, primeira política de provisão habitacional de grande escala no Brasil após o fim do BNH. Sobre o encolhimento das favelas, a meta de redução de 3,5\% deveria tomar como base o ano de 2008. No Plano Estratégico da Cidade para 2013 a 2016, a meta de redução da área ocupada por favelas foi ampliada para $5 \%$.

10. Lembrar que no caso do Morro do Bumba o terreno era um antigo lixão com muita instabilidade estabilidade de solo, incompatível para ser ocupado por tantas famílias, situação muito particular.

11. Desde a Constituição de 1988, que remoções em favelas por motivos de risco só podem ser justificadas se amparadas por laudos técnicos. Nestes casos o reassentamento é recomendado desde que sejam respeitadas condiçóes de participação da população no processo de discussáo sobre o reassentamento que por sua vez deve ser feito em área próxima à comunidade de origem.

12. Na década de 1990 o Programa Favela Bairro fez parte de uma política habitacional que promovia urbanização das favelas cariocas através da implantação de infraestrutura e serviços básicos. Este programa 
ganhou escala com o financiamento do BID chegando a 147 comunidades entre 1994 e 2008 com investimentos na ordem de 600 milhóes de dólares. Até hoje o Favela Bairro é reconhecido como uma das principais referências de programa de urbanização no Brasil e no mundo.

13. Entre as inovaçôes trazidas com o Morar Carioca, Leitấo e Delecave (2015) citam: a incorporação de equipamentos mecânicos para melhoria da acessibilidade e transporte; a intervenção mais efetiva nas moradias através da proposição de novos conjuntos habitacionais ou melhoria das moradias existentes; a ampliaçấo da participação popular durante a elaboração dos projetos e o incentivo pela busca por maior eficiência energética e sustentabilidade nos projetos. Estas inovaçôes também correspondiam às demandas do setor empresarial da construção civil que, como lembram os autores, buscavam ampliar suas atividades considerando o momento de crescimento econômico do país na época.

14. A Eco 92, Conferência das Naçóes Unidas sobre Desenvolvimento sustentável foi realizada no Rio em 1992, tendo sido muito importante para a discussão, a nível global, de modelos de desenvolvimento econômico menos agressivos ao meio ambiente. No evento foi assinada a Agenda 21 com metas para o desenvolvimento sustentável do planeta pregando a ajuda dos países mais desenvolvidos aos países em desenvolvimento, a diminuição de desigualdades sociais. Além dos chefes de Estado, o evento de 1992 envolveu a participação de 1400 Organizações Não Governamentais no Fórum Global, evento paralelo no Aterro do Flamengo, reunindo ao todo cerca de 30.000 participantes. Foi o primeiro megaevento realizado na cidade durante os anos 1990, chamando atenção internacional para a beleza da cidade que apesar de estigmatizada pela violência foi capaz de organizar bem o evento, oferecer boas condiçôes de segurança (com a participação das Forças Armadas) e excelente receptividade aos visitantes.

15. Na Inglaterra o Grand Tour fazia parte da educação dos jovens da aristocracia inglesa e consistia em viagem de quatro ou cinco anos onde jovens, acompanhados por seus tutores viajavam o mundo para conhecer diferentes culturas e contemplar a interação do homem rústico em ambientes naturais. O Gran Tour pode ser considerado como precursor do turismo visto que a partir do século XVIII começaram a surgir facilidades para este tipo de viagem como os primeiros hotéis, serviços de mensageiros, câmbio monetário e sistemas de transporte.

16. A vinda da família real portuguesa para o Brasil colaborou para introdução de novos padrôes de comportamento da cultura europeia. A visita frequente de delegaçóes estrangeiras como a Missão Francesa revelou um outro olhar sobre a cidade com ênfase para a paisagem natural e para a afabilidade de sua gente.... $\mathrm{O}$ interesse pela exploração de paisagens ainda ocultas ou pouco conhecidas, estimularam viagens pitorescas que contribuíram para documentar e ressaltar a riqueza tropical da cidade" (Terry, 2002)

17. Entre novelas da Rede Globo gravadas em favelas: Duas Caras (Aguinaldo Silva, 2008), Salve Jorge (Glória Perez, 2014), Babilônia (Gilberto Braga, 2015), A regra do jogo (João Emanuel Carneiro, 2015), I love Paraisópolis (Alcides Nogueira, 2016) e A Força do Querer (Glória Perez, 2017).

18. Entre filmes e documentários rodados na Favela da Babilônia: Orfeu Negro (Marcel Camus, 1959), Chapéu Mangueira e Babilônia - histórias do morro (Consuelo Lins, 1999), Babilônia 2000 (Eduardo Coutinho, 1999) e Tropa de Elite (José Padilha, 2007).

19. O Bar do Davi, localizado na entrada da Favela do Chapéu Mangueira na Ladeira Ary Barroso é famoso por quitutes que encantam cariocas e atraem turistas, tendo sido vencedor por mais de uma vez do Prêmio "Comida di Buteco".

20. A categoria Paisagem Cultural foi criada em 1992 pela UNESCO para poder contemplar bens culturais que conjugassem patrimônio natural e a ação do homem.

21. Os sítios reconhecidos como Patrimônio Mundial devem estar protegidas de descaracterização. As poligonais que demarcam áreas reconhecidas como patrimônio na cidade do Rio de Janeiro compreendem dois trechos do Maciço da Tijuca, onde estão localizados picos de montanha e uma poligonal na entrada da Baía de Guanabara, compreendendo uma faixa de água defronte à Praia de Copacabana passando pelo Morro do Pico e fechando-se pela Enseada de Botafogo.

22. A Trilha TransCarioca compreende toda a cadeia de montanhas desde o Morro da Urca até a Barra de Guaratiba com $180 \mathrm{~km}$ de extensão.

23. O capim colonião ou capim Mombaça (panicum 
maximum) é uma espécie forrageira de capim altamente produtiva utilizada para engorda do gado que cobria muitos morros que compóem o Maciço da Tijuca até a década de 80. Esta espécie de capim foi considerada como terror das favelas em encosta porque na ocorrência de incêndios faz o fogo de alastrar muito rápido ameaçando favelas existentes nos morros e setores dos bairros do entorno.

24. Segundo Moraes (2013), as trilhas começaram a se sinalizadas em 2007 e em 2008 quando a Secretaria Especial de Turismo do estado do Rio de Janeiro e Ministério do Turismo levaram para as comunidades da Babilônia e do Chapéu Mangueira um programa de capacitação para que moradores atuassem como guias e educadores ambientais.

\section{Referências Bibliográficas:}

ABREU, Maurício de Almeida. A evolução urbana do Rio de Janeiro. Rio de Janeiro, IPLANRIO, Zahar, 1988.

ACSELRAD, Henri. Ambientalização das lutas sociais. O caso dos movimentos por justiça ambiental. In: Estudos Avançados, vol.24 no.68. Sáo Paulo: 2010.

CARDOSO, Flora Oliveira de Souza. Rio de Janeiro Patrimônio Mundial: a "invisivel" paisagem entre a montanha e o mar. Dissertação de mestrado, UFPE, 2016.

DOVEY, KIM \& KING, Ross. Informal Urbanism and the Taste for Slums. In: Tourism Geographics vol 14, no 2. Online. Routledge Taylor \&Francis Group, 2012.

FAGERLANDE, Sérgio. A favela é um cenário: Tematização e Cenarização nas favelas cariocas. In: Revista de Arquitectura. Universidade Católica, Bogotá, 2017.

GONÇALVES, Rafael Soares. Favelas do Rio de Janeiro: História e Direito. Rio de Janeiro: Editora Pallas/PUCRIO, 2013.

Políticas públicas e o retorno das remoçôes de favelas por ocasião das chuvas de abril de 2010 no Rio de Janeiro. In: KANT de LIMA, Roberto; MELLO, Marco Antônio da Silva, FREIRE, Letícia de Luna (orgs.). Pensando o Rio: políticas públicas, conflitos urbanos e modos de habitar. Niterói: Intertexto, 2015.

LEITÃO, Gerônimo; DELACAVE, Jonas. Favela-Bairro e Morar Carioca: Reflexóes sobre o que muda e o que permanece na política de urbanização das favelas da cidade do Rio de Janeiro, ao longo de vinte anos. In: KANT de LIMA, Roberto; MELLO, Marco Antônio da Silva, FREIRE, Letícia de Luna (orgs.). Pensando o Rio: politicas públicas, conflitos urbanos e modos de habitar. Niterói: Intertexto, 2015.

MORAES, Camila. A invenção da favela ecológica: um olhar sobre turismo e meio ambiente no Morro da Babilônia. In: Estudos Sociológicos, V18 n.35, pp. 459474. Araraquara, 2013.

PECHMAN, Robert Moses. Cidades estreitamente vigiadas: o detetive e o urbanista. Rio de Janeiro: Casa da Palavra, 2002.

PEREIRA, Luiz Antônio de Souza. Pacificação do Complexo do Alemão em tempos de megaeventos esportivos na cidade do Rio de Janeiro- Brasil. In: XIII 
Colóquio Internacional de Geocrítica, El control del espacio y los espacios de control. Barcelona, 2012.

ROLNIK, Raquel. Favelas cariocas entre a montanha e o mar são patrimônio da humanidade. In Blog da Raquel Rolnik, 02/07/12. Disponível em: https://raquelrolnik. wordpress.com/2012/07/02/favelas-cariocas-entre-amontanha-e-o-mar-sao-patrimonio-da-humanidade/

SANCHEZ, Fernanda. A cidade reinventada: o papel do turismo urbanístico em Curitiba. In: 6o Encuentro de Geógrafos de América Latina: Territorios en redefinición, lugar y mundo en América Latina. Buenos Aires, 1997.

SEBRAE. Guia de Bolso Favelas Rio. Rio de Janeiro, 2014

SINAY, L., SINAY, M.C.F., PENA, I.A.B.. Parque Natural Municipal da Paisagem Carioca (RJ): ecoturismo e sustentabilidade. In: Revista Brasileira de Ecoturismo, São Paulo, V.7, n.3, ago /out. pp. 500-516, 2014.

TERRY, Tatiana. Praia de Copacabana o espaço do cariocaHistória, Forma, Usos e Significados. Dissertação de mestrado, PROURB FAU UFRJ, 2002.

TERRY, Tatiana; CARVALHO, S.A., JAVOSKI, D.E.A. Morar Carioca Verde - Urbanização das Favelas da Babilônia e Chapéu Mangueira. Reflexóes sobre o discurso e resultados do projeto-piloto em sustentabilidade para as favelas cariocas. In: Anais do II Congresso Internacional de Habitação Coletiva Sustentável. São Paulo, 2016.

URRY, John. O olhar do turista: lazer e viagens nas sociedades contemporâneas. São Paulo: Studio Nobel: SESC, 2001.

VAINER, Carlos B. Pátria, empresa e mercadoria. Notas sobre a estratégia discursiva sobre o planejamento urbano estratégico. In ARANTES, O.; VAINER, C. e MARICATO, E. A cidade do pensamento único: desmanchando consensos. Petrópolis: Vozes, 2000.

VALLADARES, Lícia do Prado. A invenção da favela: do mito a favela.com. Rio de Janeiro: Editora FGV, 2005.

VILLAMIZAR, Laura Cristina Gómez e CUNHA, Neiva Vieira. A "favela sustentável": conflitos no uso e no manejo dos recursos naturais nas favelas do Chapéu Mangueira e da Babilônia (RJ). In: CUNHA, N.V, FREIRE,L.L, MACHADO MARTINS, M. e VEIGA, F.B. (orgs.). Antropologia do Conflito Urbano: Conexóes Rio-Barcelona. Rio de Janeiro: Lamparina/CNPQ/LeMetro, 2016.

\section{Material complementar:}

"Rio +20: muro em UPP é derrubado para prefeito de Nova York ver a Baía de Guanabara”. Disponível em UOL Notícias: https://noticias.uol.com.br/cotidiano/ultimasnoticias/2012/06/19/rio20-muro-em-upp-e-derrubadopara-prefeito-de-nova-york-ver-a-baia-de-guanabara.htm

"Prefeito de NY não precisava ter medo do 'Ozama da Babilônia', diz grafiteiro censurado durante a Rio+20". Disponível em Uol notícias: https://noticias. uol.com.br/cotidiano/ultimas-noticias/2012/06/25/ prefeito-de-ny-nao-precisava-ter-medo-do-ozama-dababilonia-diz-grafiteiro-censurado-durante-a-rio20. htm?cmpid=copiaecola

Relatório: Rio Cidade Sustentável- Desenvolvimento Sustentável feito por pessoas e negócios, junho de 2012. Disponível em: http://cebds.org/wp-content/ uploads/2016/10/Relat\%C3\%B3rio-final-Rio-CidadeSustent $\%$ C3\%A1vel-002.pdf

Dossiê de Candidatura do Rio de Janeiro a sede dos Jogos Olímpicos e Paraolímpicos de 2016. Autoridade Pública Olímpica, Rio de Janeiro, 2009. Disponível em: http:// www.apo.gov.br/index.php/matriz/a-matriz-e-o-dossiede-candidatural

Plano Estratégico da Prefeitura do Rio de Janeiro2009-2012- Pós 2016 - o Rio mais integrado e competitivo. Prefeitura da Cidade do Rio de Janeiro, 2009. Disponível em: http://www.rio.rj.gov.br/ dlstatic/10112/6616925/4178940/planejamento_ estrategico_site_01.pdf

Plano Estratégico da Prefeitura do Rio de Janeiro2013-2016- Pós 2016 - o Rio mais integrado e competitivo. Prefeitura da Cidade do Rio de Janeiro, 2013. Disponível em: http://www.rio.rj.gov.br/ dlstatic/10112/2116763/4104304/planejamento_ estrategico_1316.pdf 